\title{
GSM Base Stations Location Monitoring using Geographic Information System
}

\author{
Kuboye B. M., Dada O. A., Akinwonmi F. C. \\ School of Sciences, Federal University of Technology, Akure, Nigeria \\ kubonline@yahoo.co.uk, abisoyedada@gmail.com, shadian2003@yahoo.co.uk
}

\begin{abstract}
Global System for Mobile Communication (GSM) is a digital system developed to meet the desires of the entire public. As the population of a particular area, city or country increases, the number of mobile subscribers increases too. GSM network operators have to reduce congestion on their networks in order to satisfy their subscribers, therefore, a means of monitoring the base stations' locations and the geographical area of where they are located are important factor to achieve this purpose. This work provides a simple step-by-step approach on how to monitor the location of the base stations. A review of GSM and Global Positioning System (GPS) technology and their applications to the Geographic Information System (GIS) are presented. The means of taken the coordinates of base stations using a GPS device is also presented. ESRI's ArcView application software was used to design the map that shows the location of the base station and thereafter was integrated into the web. It concluded with the recommendation to GSM operators in Nigeria. If the recommendations are given necessary attention, the planning and optimization of cell sites will be enhanced and thereby reduce congestion on network. As a result, the performance of Network will improve, and it will give rise to subscribers' satisfaction and increasing profit returns to the operators.
\end{abstract}

Index Terms - GIS, GPS, GSM, Base station, Subscriber

\section{INTRODUCTION}

The goal of development of wireless system is to enable communication everywhere and at any time. The success experienced so far in telecommunication have depended on the progress made in the areas of communication systems, microletronics, software and hardware technology, security and signal processing. The most popular of all the current wireless systems is Global System for Mobile Communication (GSM) where there is roaming freedom within and across networks. Also, communication everywhere with everybody is possible except for people who are in the rural areas where there is still no GSM coverage.Geographic Information System (GIS) integrates hardware, software, and data for manipulating all forms of geographically referenced information. It provides the framework for all forms of spatial data storage, retrieval, analysis, display, reporting and modeling [1]. Geographic Information System is used to process maps of one type or another. An individual map contains a lot of information which is used in different ways by individuals or organizations [2]. These maps are used in diverse applications, ranges from locating telephone wires and water distribution pipelines to displaying the extent of deforestation in a region. The traditional maps are static, therefore, difficult and expensive to keep to date. Also, maps exist as separate sheets and the use of the map depends on the coverage. The complexity of the map often requires experts to extract data of interest for specific purpose [3]. GIS technology has cut attention of professionals because of its capability to incorporate graphical features with tabular data to measure real world problems. GIS helps planners analyze problems quickly and thoroughly to enable them formulate solutions that will achieve long-term goals [1].

The GSM has become one of the wireless technologies that has direct impact on people and as a result has gained acceptance by everyone. At present, wireless operators are trying to have higher level of network efficiency to gain the acceptance of customers. Geographic Information Systems (GIS) is now used by wireless operators to ensure their businesses operate at high efficiencies. A huge crowd from different parts of Nigeria are always gathered during many festivals like the Osun-Oshogbo festival, the Sokoto annual horse race event, the Argungu fishing festival. Most cities in Nigeria especially state capitals normally experienced a population surge due to rural urban drift. Most of these state capitals have opportunities that are not present in sub-urban areas. As a result, there must be a way of knowing the location of base stations, their distance to each other, so that when the need of having more base station arises, there will be proper dimensioning and all subscribers in all the locations will have fair and proper connections.

\section{METHODOLOGY}

In order to design and develop a basic web-enabled Geographic Information System for locating MTN base 
stations in Akure North and South Local government, various methodologies were reviewed to have information for the design of the system. Personal tour of the MTN base stations in Akure North and South Local governments, to get the GPS coordinates were done. The GIS maps downloaded from Google Earth and the GPS coordinates taken for MTN Base Stations were analysed. Thereafter, ESRI's Arcview software was used to convert the maps to raster maps for digitalization. The coordinates were then inserted on the digitized map. The raster map and the digitized map showing the MTN base stations were linked to the website which was designed with PHP and HTML. The results were analysed, then the conclusion and the recommendations were drawn.

\section{SYSTEM REVIEWS}

\section{A. Global System for Mobile Communications} (GSM)

The GSM was developed to create a common European mobile telephone standard but has been accepted all over the world. Discussions were held between 1982 to 1985 to decide either to build an analog or digital system. Upon several field tests, a digital system was adopted for GSM. The narrowband time division multiple access and frequency division multiple access (TDMA/FDMA) solution was chosen in May 1987 [4].

GSM has been standardized to use $900 \mathrm{MHz}$, $1800 \mathrm{MHz}$, and $1900 \mathrm{MHz}$ radio band which is normally called the frequecy of the network [5]. The $900 \mathrm{MHz}$ and $1800 \mathrm{MHz}$ used the same base-band signals, but operate on different carrier frequencies. The radio frequency separation between the matching uplink and downlink carrier for $900 \mathrm{MHz}$ is $45 \mathrm{MHz}$ while that of $1800 \mathrm{MHz}$ is $90 \mathrm{MHz}$ as seeing in fig 1[4].

\section{Downlink Channel}

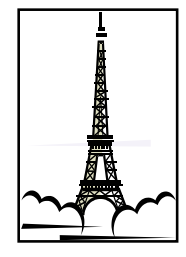

BS

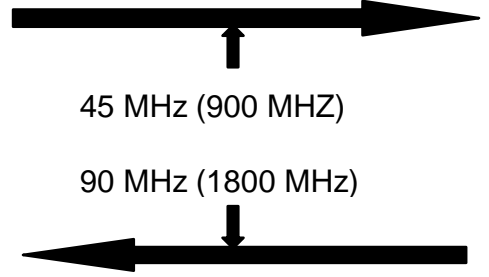

Uplink Channel

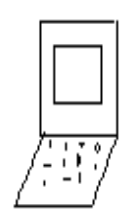

MS
Figure 1. GSM Duplex Radio (Source: [4])

The GSM network is made up of geographic areas. As shown in Fig. 2., these areas include cells, location areas (LAs), MSC/VLR service areas, and public land mobile network (PLMN) areas. A cell is the coverage area of a given radio by one base transceiver station. The GSM network identifies each cell via the cell global identity (CGI) number assigned to each cell. The location area (LA) is a group of cells and subscribers are paged in the area. One or more base station controllers serve each LA, but with a single MSC (see Fig.1). Each LA is assigned a location area identity (LAI) number. An MSC/VLR service area represents the part of the GSM network that is covered by one MSC and which is reachable, as it is registered in the VLR of the MSC [6].

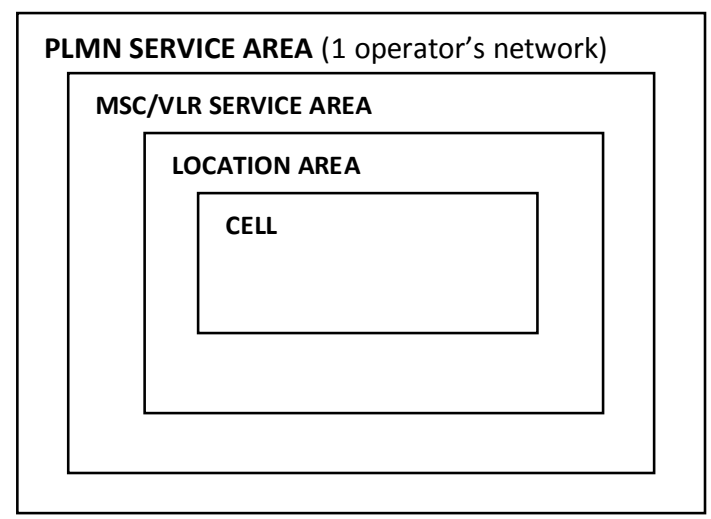

Figure 2. PLMN Service Area (Source:[6])

The PLMN Network is an area served by one GSM operator. The GSM subsystem consists of three major components and they are Mobile station (MS), Base Station System (BSS) and Switching System (SS) as shown fig. 3.

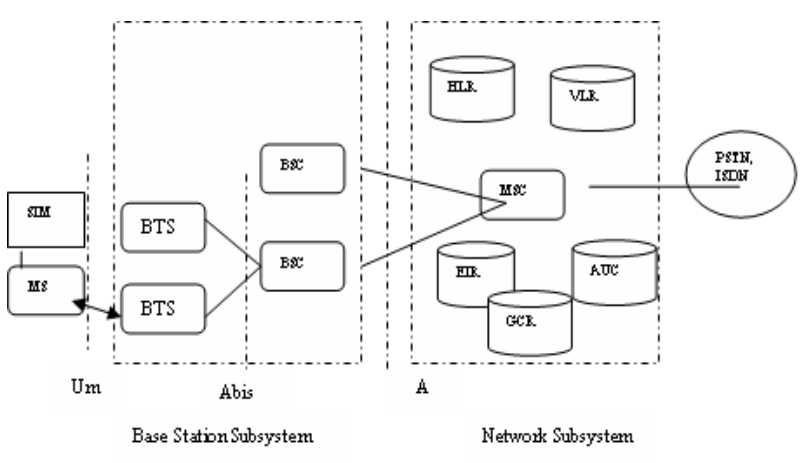

Figure 3. GSM Network Subsystems (source: [7])

The Mobile station consists of Mobile Equipment (ME) (mobile phone) and Subscriber Identity Module (SIM). SIM provides personal mobility so that subscriber can have access to subscribed services irrespective of a specific ME [7]. SIM has a microprocessor and memory that holds information on the chip even if the SIM card is deactivated [5]. SIM is stored inside the ME to identify each subscriber on the GSM Network through International Mobile Subscriber Identity (IMSI) number.

A GSM network is comprised of many base station subsystems (BSSs). The BSS consists of base station controllers (BSCs) and the base transceiver stations (BTSs). The BSS performs the necessary functions for monitoring radio connections to the Mobile Station (MS), coding and decoding voice, as well as, rate adaptation to and from the wireless network. The 
covered area of a cellular network is divided into smaller areas called cells. Each cell is connected to a base station system, which communicates simultaneously with all mobiles within the cell, and passes traffic to the Mobile Switching Center. The Base Station System is connected to the ME via a radio interface [8].

The central component of the Network switching subsystem (SS) is the Mobile Switching Center (MSC). MSC is the link between the Base station subsystem and network switching subsystem of the GSM Network (Fig 5). Also it acts as the link between the cellular system and the PSTN. MSC is responsible for performing call routing to a roaming subscriber, registration, authentication, location updating, handovers and subscriber-related functions [7]. These services are provided in conjunction with several functional database entities, which together form the Network switching system. The databases are home location register (HLR), visitor location register (VLR), authentication center (AUC), equipment identity register (EIR), group call register (GCR), message center (MXE), mobile service node (MSN), and short message center (SMSC). Signaling between functional units in the MSC uses signaling system number 7 (SS7). SS7 is widely used for trunk signaling in the ISDN and in public networks. [7]. Signaling allows different functional units to interwork successfully and provide a data communication path between network nodes [9].

GSM subscribers could be anywhere within the network when they make call, the MSC must ensure that the calls are routed to the appropriate destination. In other to simplify this network management function, the entire PLMN network is divided into service areas and each service area is allotted one MSC to monitor the activities. MSC are interconnected to monitor the movement of subscribers. Some MSC are called gateway MSC (GMSC). A gateway is a node used to interconnect two networks. The GMSC is the interface between mobile network and other mobile network or any other network. All incoming calls to the PLMN from another PLMNs, fixed wireless or landlines must pass through the gateway. Gateway MSC works as an incoming transit exchange for the GSM/PLMN. Gateway MSC contains interconnecting functions to make interconnections between two PLMNs, PSTN or fixed wireless system. They also route incoming calls to the proper MSC within the Network [10]. In summary, the role of MSC is to manage the communications between the GSM users and other telecommunication users.

\section{B. Global Positioning System (GPS)}

The Global Positioning System (GPS) is a spacebased global navigation satellite system (GNSS) that provides reliable location and time information in all weather and at all times and anywhere on or near the Earth when and where there is an unobstructed line of sight to four or more GPS satellites [11]. GPS consists of three segments: the space segment, the control segment, and the user segment as seen in fig. 4. The Space segment has 24-satellite constellation. Each GPS satellite transmits a signal, which has a number of components, namely, two sine waves called carrier frequencies, two digital codes, and a navigation message. The digital codes and the navigation message are added to the carriers as binary bi-phase modulations [12]. The carriers and the codes are used mainly to determine the distance from the user's receiver to the GPS satellites. The navigation message contains the coordinates of the satellites as a function of time.

The main function of the operational control segment is to track the GPS satellites in order to determine and predict satellite locations, system integrity, and other important information [12]. The information is then packed and uploaded into the GPS satellites through the S-band link. The User segment includes all categories of users. Users receive the GPS signals on the GPS receiver to determine his or her position anywhere in the world. GPS is available to all users around the world at no cost.

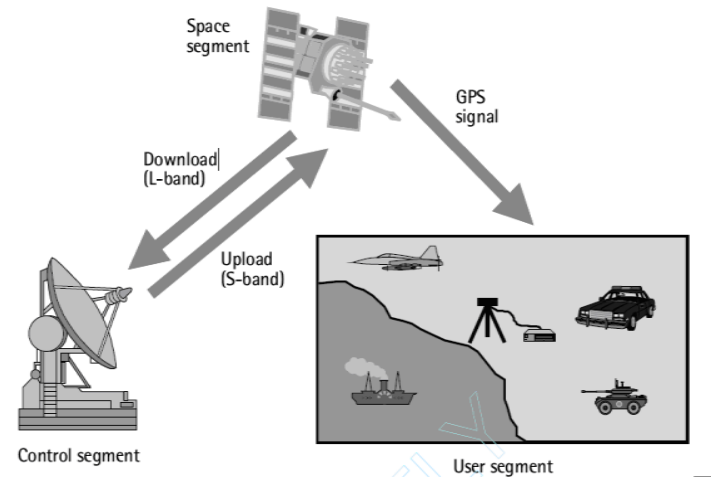

Figure 4. GPS Segments (source: [12])

\section{Geographic Information System (GIS)}

GIS is a system for capturing, storing, checking, integrating, manipulating, analysing and displaying data related to positions on the Earth's surface [2]. GIS is also defined as a modern technological tool for effective and efficient storage, retrieval and manipulation of spatial and non-spatial data for deriving scientific, management and policy making information [1]. Typically, Geographical Information System is used for handling maps of one kind or another. These might be represented as several different layers where each layer holds data about a particular kind of feature. Each feature is linked to a position on the graphical image on a map and a record in the attribute table [13].

\section{GPS and GIS Integration}

Spatial or geographic data can be obtained from a variety of sources such as existing maps, satellite imagery, and GPS. GPS is used to collect the GIS field data in a digital format in either real-time or post processed mode. Since GIS can accept geographic data 
from a variety of sources, once the information is collected, it is stored as a collection of layers in the GIS database. Afterwards, GIS is used to analyze the data in order to take meaningful decisions.

\section{RELATED WORK}

Some researches related to the use of GIS have been done and presented in literatures. A research based on the application of GIS in tourism in Nigeria was presented [14]. It discusses how a web-based GIS can be used to gather and analyse the data regarding tourisms for efficient management and promotion in Nigeria. Ajala described how MTN Nigeria Communication is using GIS capabilities with GSM network monitoring tools to find areas where subscribers are having low quality signals [15]. A recent work was published by Fosu describing how GIS technology can enhance revenue mobilization in the local government [1]. The work describes comprehensively the functionalities of GIS application software developed for local authorities in Ghana for internal revenue mobilization. The work clearly shows how an integrated GIS database technology tool is capable of providing a more efficient means of collecting, tracking and managing of Local Government revenue. Another work demonstrated how GIS can be used to optimize GSM system using measurement report (MR) [16]. The MR is a report from cell that shows the number of mobile station (MS) connected. The report is sent to the cell every 480s so as to show that the MS sees the BTS and base transceiver station (BTs) sees the MS. This MR is then integrated into the cellular office database which is connected to the GIS software to serve as points' location for all MS connected to the cell. This work enables the GSM operator to know the MS distribution, in other words, the distribution of subscribers within the cell.

Vincezo Barrile [17] use investigated with the help of GIS whether the fixed installations for cellular phone is compatible with the health of citizens and check if the values of exposures to electromagnetic fields produced by them are within the limits set by law [17]. This was realised by using GIS to store, manage, and process all data relating to the electromagnetic fields produced by the antennas of all the installed cellular infrastructures within the city. The result will help the operators to know how to plan the installation of their infrastructures to avoid health risk to people. A novel analysis method for analysing the cell coverage in GSM network employed GIS system in carrying out the work effectively [18]. The method involves collection and analysis of mobile measure data from the operation and maintenance center (OMC) system of the MSC. Thereafter, cell coverage chart was drawn using GIS software and the problem cells which have deviated from the coverage were identified on the graph.

\section{METHODS OF DATA ACQUISITION}

The data used in this work were collected through the use of GPS that captures the coordinates in terms of longitudes and latitudes of the base stations in Akure North and South local governments of Ondo state, Nigeria. Thereafter, Google earth was used to capture the area views of the two local governments.

Google Earth displays satellite images of varying resolution of the Earth's surface, thus, allowing users to see things like cities and houses looking perpendicularly down or at an oblique angle. It allows users to search for addresses of cities, towns in a country using coordinates of the area to be visited. The satellite image of some parts of Akure from Google Earth's is shown in Fig. 5.

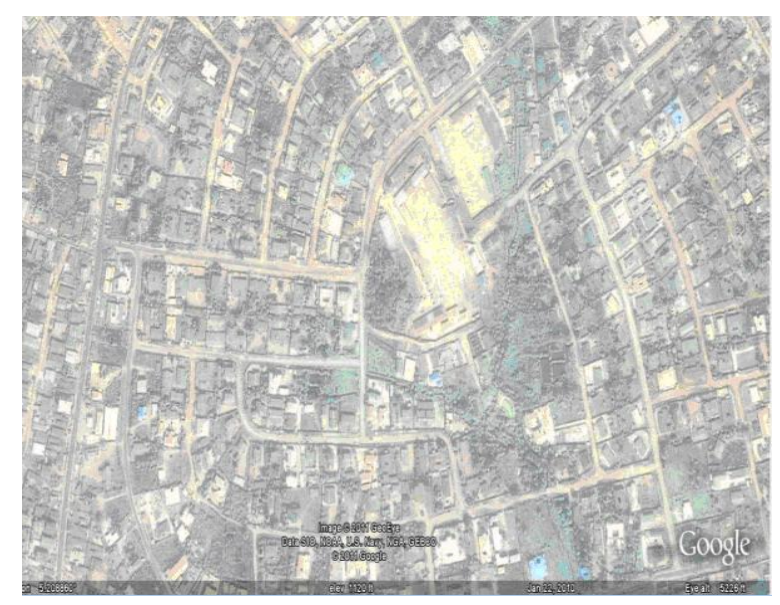

Figure 5. A part of Akure as shown in Google Earth

\section{A. Geo-referencing and Mosaicing of Images}

Georeferencing deals with the definition of existence of something in physical space, that is, to establish its location in terms of coordinate systems. The term is used when establishing the relationship between raster or vector images and coordinates. It is also use to determining the spatial location of other geographical features. The four specific control points for the geo-referencing on the image with a yellow pin on each point are shown in Fig. 6. At each point, the coordinate (longitude and latitude) was taken. These images are then imported to ESRI'S Arc View for georeferencing. Thereafter, the images were mosaiced, that is, small different images were joining together so as to get the target image. The Imagine Analysis tool in ESRI's Arc View helped to link the images together. In the process of capturing images, the images are saved 
in such a way that they overlap each other. This overlap helps in the joining of all the available images smoothly into one whole image as shown in Fig. 7.

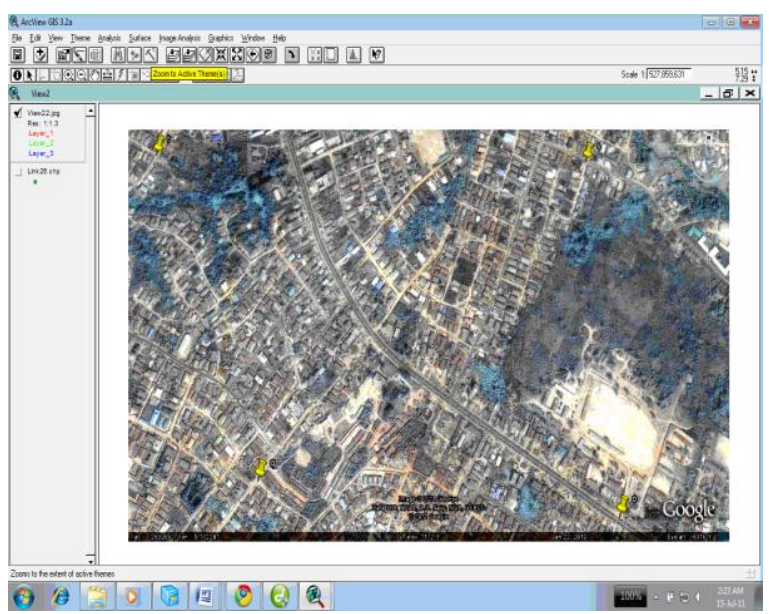

Figure 6. A Georefenced Image of a part of Akure

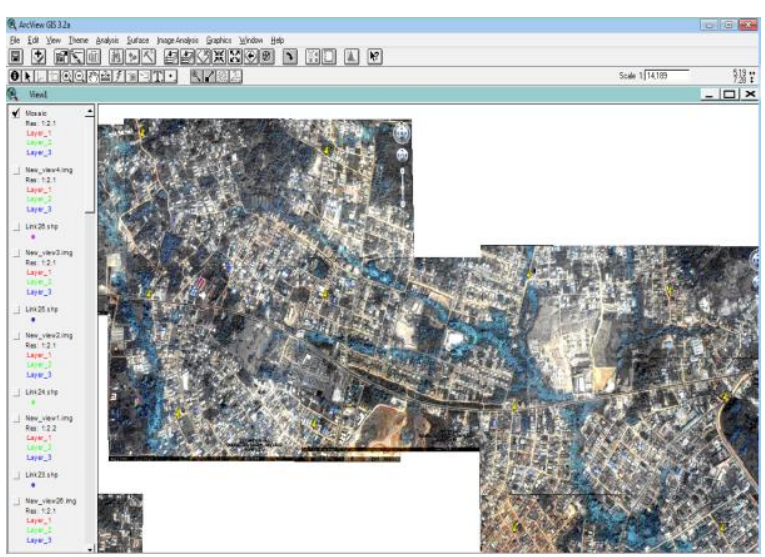

Figure 7. A Mosaic Image of a part of Akure

\section{B. $\quad$ Creating the digitized map}

The boundary of Akure North and South local governments was carved out from the mosaic image and then converted to shape files using the query builder as shown in Fig. 8.

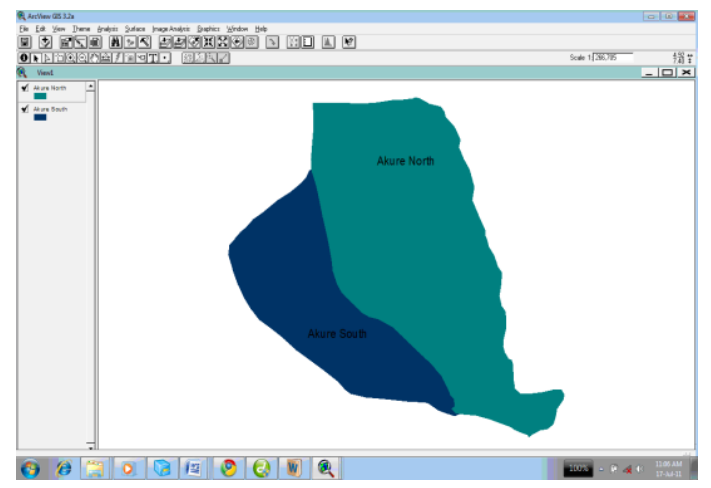

Figure 8. Digitized map of Akure

\section{GIS - Base station GPS location integration}

The coordinates of the base stations that were collected using GPS tool were exported to ArcView to form the attribute table. These coordinates were then added as an event theme. As soon as event theme was added, the coordinates that were activated immediately transforms to the locations of base stations on the map as shown in Fig. 9. The map clearly shows the location of all the base stations of MTN in Akure north and south local governments of Ondo state, Nigeria as taking by the GPS system.

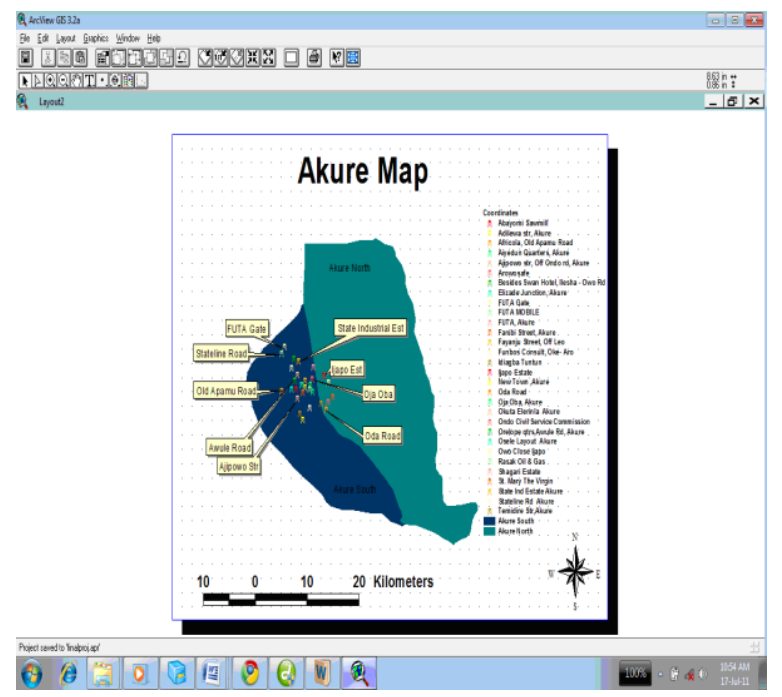

Figure 9. A Layout of digitized map of Akure

\section{WEB IMPLEMENTATION AND INTERPRETATION}

The digital map of Akure North and South local governments showing the locations of the MTN base stations are integrated into the web as shown in fig. 10 and fig. 11. The essence is to make the base station locations accessible through Internet. If there is any complain of congestion or poor signals in any part of the coverage area by the subscribers, both the subscribers and the operators can know the location of the base station and the nearby base stations. Also, it will also help the operator to validate the complains of the subscribers and will to know if there is will be need of optimization of the base stations or erected of new one. The poor signal might be as a result of long distance of subscribers who have just moved into the area from the available base station. On the other hands, if it is congestion, it might result from surge in the number of people living the area thereby making the infrastructures of the base stations insufficient for them. 


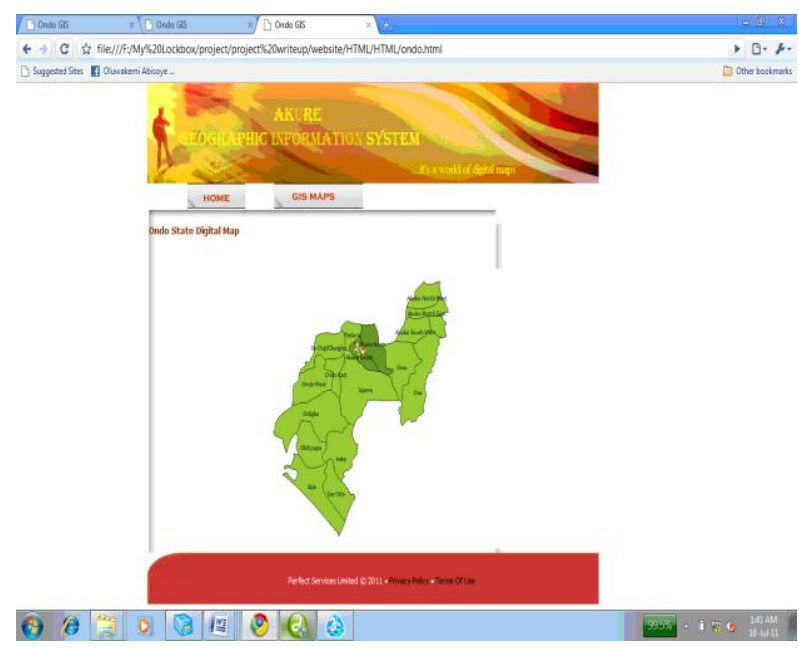

Figure 10.

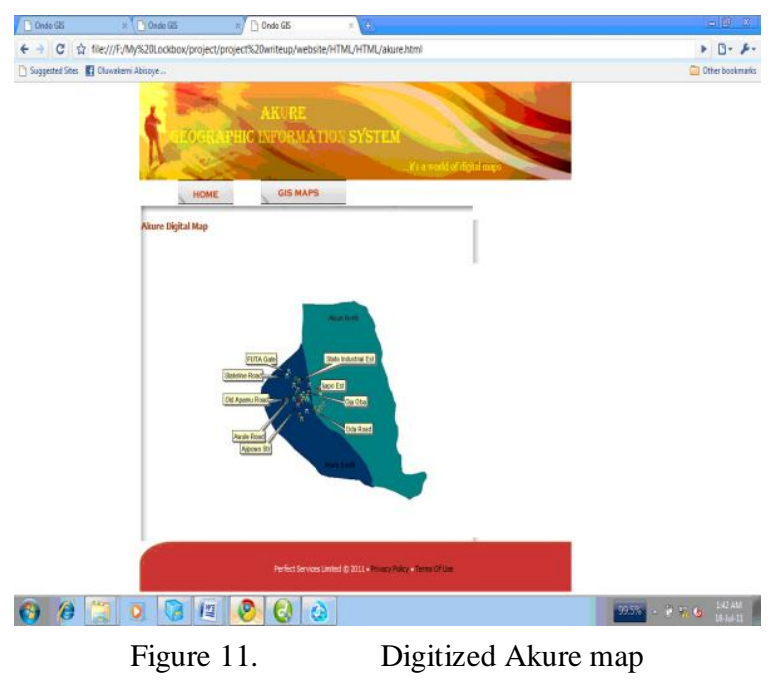

VII. CONCLUSION

GSM is designed to meet the needs of the entire public. As the population of a particular area, city or country increases, the number of mobile subscribers increases too. For any GSM network provider to have optimum profit returns, they must find all means of satisfying their subscribers. This work has shown how GSM operators can easily monitor and locate their Base stations. Also, they will know how population increases by using the Google map to know when some areas are inhabited by people.

\section{RECOMMENDATION}

It is very thereby recommended for GSM network provider to have a this type of systems in other to have proper dimensioning of their network at any point in time.

\section{REFERENCES}

[1] Fosu C., And Ashiagbor G., GIS Application for Local Government Revenue Mobilization. Proceedings of Global Geospatial Conference, Québec City, Canada, 2012.

[2] FadahunsI, J.T., A Perspective View on the Development and Applications of Geographical Information System (GIS) in Nigeria. Pacific Journal of Science and Technology, 11(1):301-308, 2010.

[3] Douglas F.D., Cartographic Development in GIS, 2000

[4] Kuboye B. M., Alese B. K., Fajuyigbe O., Adewale O. S. (2011). "Development of Models for Managing Network Congestion on Global System for Mobile Communication (GSM) in Nigeria", Journal of Wireless Networking and Communications, 1(1): 8-15. DOI: $10.5923 /$ j.jwnc.20110101.02

[5] Harte L, Levine R. and Livingston G.,1999. GSM Superphones. McGraw Hill 71: 45-47.

[6] www.iec.org online /tutorials/gsm

[7] Scourias J. (1997) "Overview of the Global System for Mobile Communication"

[8] Perianan R. and Fahham F. J. (1996). "Performance Issues of Cellular Networks" www.dsc.doc.ic.uk/Surprise--96/Journal

[9] Peter BE (2002). "GSM Raw Capacity Solution” Ericsson Review (2).

[10] Mehrotra A. (1997). "GSM System Engineering", Artech Home, Inc.

[11] Lita I, Visan D. A. and Popa I, Localization System Based on enhanced software GPS Receiver. 29th International Spring Seminar on Electronics Technologies, IEEE, ISBN: 14244-0550-5, 2006.

[12] Wells et al., 1987. Guide to GPS Positioning. Fredericton, New Brunswick: Canadian GPS Associates.

[13] ESRI, 2003. www.esri.com

[14] Fajuyigbe O., Balogun V.F. and Obembe, Web-Based Geographical Information System (GIS) for Tourism in Oyo State, Nigeria. Information Technology Journal, Asian Network for scientific Information, Vol 6:5, 613-622, 2007.

[15] Ajala I, (2005). "GIS and GSM Network Quality Monitoring: A Nigerian Case Study" Direction magazine. http://www.directionsmag.com/articles/gis-gsm-network-quality-monitoring-a-nigeriancase-study

[16] Dong L New Method of Optimizing GSM System using Measurement Report, 2005.

[17] Vincenzo B., Giuseppe A. and Giuliana B., GIS Supporting the Plan of BTS for mobile network in Urban Context. WSEAS Transac- 
tions on Communications, Issue 8, Volume 8, 2009.

[18] Lan L., Intelligent GSM Cell Coverage Analysis System Based on GIS. Journal of Computers, VOL. 6, NO. 5, 2011.

O. A. Dada, born in 1985. B.Tech. in the Federal University of Technology, Akure from Nigeria. Her main research interests include Wireless communication and Geographical Information System applications.

F. C. Akinwonmi, born in 1973. M.Tech. candidate in the Federal University of Technology, Akure from Nigeria. Her main research interests include Computer Security and Geographical Information System Applications.

B. M. Kuboye, born in 1971. Ph.D. and lecturer in the Federal University of Technology, Akure from Nigeria. $\mathrm{He}$ is member of the Nigeria Computer Society. His main research interests include Computer and Wireless Networks Communication and Geographical Information System. 